\title{
Comparison Between Characteristics of Products With Ecolabel and the Ones Without Ecolabel
}

\begin{abstract}
ANTONINA TEMEA ${ }^{1 *}$, VALENTIN NEDEFF ${ }^{1,2}$, MIRELA PANAINTE-LEHADUS ${ }^{1}$, CLAUDIA TOMOZEI ${ }^{1}$
'Vasile Alecsandri University of Bacau, Department of Environmental Engineering and Mechanical Engineering, 157 Calea Marasesti, 600115, Bacau, Romania

2Academy of Agricultural and Forestry Sciences Gheorghe Ionescu Sisesti, 6 Marasti Blvd., 011467, Bucharest, Romania

The main objective of this paper is to analyze and compare the characteristics of eco-labeled products (energy consumption, $\mathrm{CO}_{2}$, annual operation cost, price difference, payback period) versus the unlabeled products from category efectrical and electronic products. The work synthetically presented some of the relevant conclusions of an eco-marketing research in Romania. It is useful for producers and distributors in order to increase their market position and gain competitive advantages.
\end{abstract}

Keywords: eco-label, electrical products, energy consumption

The aim of the study was to compare the characteristics of eco-labeled products with the unlabeled products from category electrical and electronic products.

The ecological label has been implemented by the European Commission in 1992 in order to encourage the market of products and services with low negative impact on the environment[1]. Today there are well over 100 different eco-labels in the world, most of them used somewhere in Europe [2].

To live sustainably, the Earth's natural resources must be used at a pace they can recover. However, our consumer society exercised enormous pressure on the planet. Ecological footprint of the Europe is one of the largest on the planet. If the rest of the world population would live like Europeans would be necessary the resources of more than two planets such as Earth for support [3].

For the modern society to become sustainable in the long term, the products that have lowest negative effect on the environment should become the accepted standard [4-6].

When developing EU Ecolabel criteria for products, the focus is on the stages where the product has the highest environmental impact, and this differs from product to product [5]. Other products, such as electronic equipment, have a very high environmental impact during their use phase, so criteria will focus on the efficiency of their energy consumption [6].

The Ecolabel applied to electrical products and household appliances guarantees that these products consume less energy during the use, guarantees a high level of performance, are quality products with durability and not contain substances hazardous to the environment and to human health [7].

There are several benefits of using labels, among which stands out the possibility of obtaining better prices, creating a positive image of the brand, creating good relations with public authorities and the opportunity to identify ways to reduce costs [8].

Some scattered anecdotal evidence shows that sales have increased when an eco-label has been obtained, but there is no statistical data in general to show the market power an eco-label may confer on a product [9]. Producers however continue to apply for and pay for eco-labels, indicating they have some market value. Also, it is difficult to separate out the market impact of the eco-label from other factors which influence a products' market share [10].

Romania is among the countries where the notion of green products started to widen. On the other hand, for them there are no obvious and established standards for product quality or environment. The consumers can find imported goods that are produced in the areas under license and which have recycling labels, but there is a total lack of recycling infrastructure in their market [11] .

The paper presents the main preliminary results of a market survey conducted in 2010-2013, the LIFE + project - Promoting green products, a study carried out in Romania in order to create a national register of green products.

\section{Experimental part}

The market research took place in Bacau, Romania during to 2010-2013, targeting a total of 11 market places, namely 7 supermarkets and 4 department shops/malls. The choice of the specific market places was based on their relevance to the consumers in the region, the volume of products they sell and the presence of specific categories of products of interest under the present study.

The product categories analysed are the following ones (GREEN PRO, 2010; GREEN PRO, 2013 [12,13]):

-Electric lamps

-Laptop Computers

-Monitor Pc

-Refrigerators

-System unit

-Televisions

-Vacuum cleaners

-Washing machines

For each product category the following main parameters were calculated: $\mathrm{CO}_{2}$ emissions $(E m)$, price difference $(P D)$, annual operational costs $(A O C)$, and payback period (PP).

\section{$\mathrm{CO}_{2}$ emissions (Em)}

This parameter was calculated based on the energy consumption $(E C)$ of the analysed products specified on the Energy label of each product ( publication of these data is mandatory for all appliances sold in the EU and these must be clearly displayed on each appliance at the point of sale). The energy consumption ( $E C$ ) was calculated as an average value for each sub-category (eco and non eco

\footnotetext{
*email: ninatemea@yahoo.com, Phone: 0749541716
} 
products). The $\mathrm{CO}_{2}$ emissions ( $\left.\mathrm{Em}\right)$ were then calculated by using the methodology described in the British Standard PAS 2050:2008 Specification for the assessment of the life cycle greenhouse gas emissions of goods and services as well as the Guide to PAS 2050 How to assess the carbon footprint of goods and services, using the conversion factors from the Greenhouse Gas Protocol (GHG) [6].

Thus the calculation is:

$$
E m=E C * C
$$

where: $E m$ : $\mathrm{CO}_{2}$ emissions [t], Ec: Energy consumption [kWh], $\mathrm{C}$ : Conversion Factor [for Romania 0.337 in $\mathrm{CCO}_{2} /$ $\mathrm{kWh}]$

\section{Price difference $(P D)$}

The difference in the sale price between eco and non eco products was calculated, based on the mean price found in the marketplaces of the two sub-categories, as:

$$
P D=P e-P n e
$$

where: PD: Price difference [euro], Pe: Price of eco product [euro], Pne: Price of non eco product $[\in]$

\section{Annual operational costs ( $A O C, A O C D)$}

This parameter refer to the standard operational costs of the analysed products, that entail energy and water consumption (only for washing machines). Consumption data provided by each producer in the product label were used for the calculation (the power consumption is mandatory to be displayed on the device, EU Directive 92/ $75 / E C)$, together with the current prices for households for electricity and water in Romania. Other costs (e.g. cost of detergents for washing machines, cost of auxiliary materials like removable dust containers in vacuum cleaners, maintenance costs where applicable, etc.) were not considered for the AOC calculation.

The following assumptions have been made:

The lights bulb is used for six hours a day, every day over a year.

For the washing machine I considered : washing program for $1 \mathrm{~h}$ at $40^{\circ} \mathrm{C}$ at load weights $4.5 \mathrm{~kg}$ and that a machine will be used twice a week.
The annual energy consumption of the TV, in kWh, calculated based on the manner (on) in operating condition for $4 h$ a day and 365 days a year.

For the refrigerators: the systems refrigeration are permanently on there was no need to add a constant for periods of use.

Concerning Personal Computers (System Unit and Monitor) and Laptop Computers the energy consumption is calculated for eight hours a day for five days a week.

The Vacuum cleaners are considered used an hours a week .

The following formula was used for the calculation:

$$
A O C=(P e l \cdot E C)+(P w \cdot W C)
$$

where: $A O C$ : Annual operational cost [euro/y], Pel: Price of electricity [euro/kWh], Pw: Price of water [euro/L], EC: Energy consumption per year $[\mathrm{kWh} / \mathrm{y}], W C$ : Water consumption per year [L/y]

The difference in annual operational costs between eco and non eco products (AOCD) was then calculated as:

$$
A O C D=A O C n e-A O C e
$$

where: $A O C D$ : Difference in annual operational costs [euro/ y], AOCne: Annual operational costs of non eco product [euro/y], AOCe: Annual operational costs of eco product [euro/y]

\section{Payback period (PP)}

Payback period was calculated based on difference in price and in annual operational costs between eco and non eco products, in order to identify in how many years a supposedly higher initial purchase cost of an eco product can be recovered by lower annual operational costs.

The formula used was:

$$
P P=P D / A O C D
$$

where: PP: Payback period [y], PD: Price difference[euro], $A O C D$ : Difference in annual operational cost [euro/y]

\section{Results and discussions}

From the market research the following products were identified (table 1).

\begin{tabular}{|c|c|c|c|}
\hline Product category & $\begin{array}{c}\text { Products } \\
\text { identified }\end{array}$ & $\begin{array}{c}\text { Eco products (number } \\
\text { and \%) }\end{array}$ & Non eco products \\
\hline Electric lamps & 151 & $14(9.3 \%)$ & 137 \\
\hline Laptop Computers & 36 & $8(22.2 \%)$ & 28 \\
\hline Monitor Pc & 18 & $3(16.7 \%)$ & 15 \\
\hline Refrigerators & 116 & $15(12.9 \%)$ & 101 \\
\hline System unit & 22 & $5(22.7 \%)$ & 17 \\
\hline Televisions & 108 & $29(26.9 \%)$ & 79 \\
\hline Vacuum cleaner & 37 & $14(37.8 \%)$ & 23 \\
\hline Washing machines & 140 & $5(3.6 \%)$ & 135 \\
\hline Total & 628 & $93(14.8 \%)$ & 535 \\
\hline
\end{tabular}

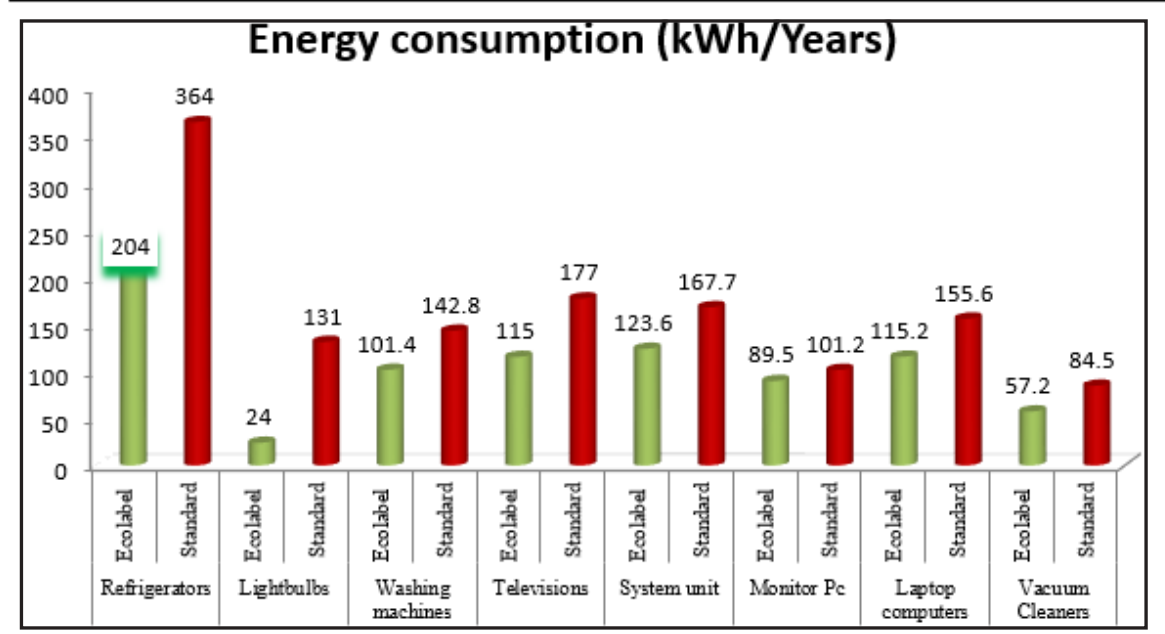

Table 1

PRODUCTS IDENTIFIED DURING THE MARKET RESEARCH 


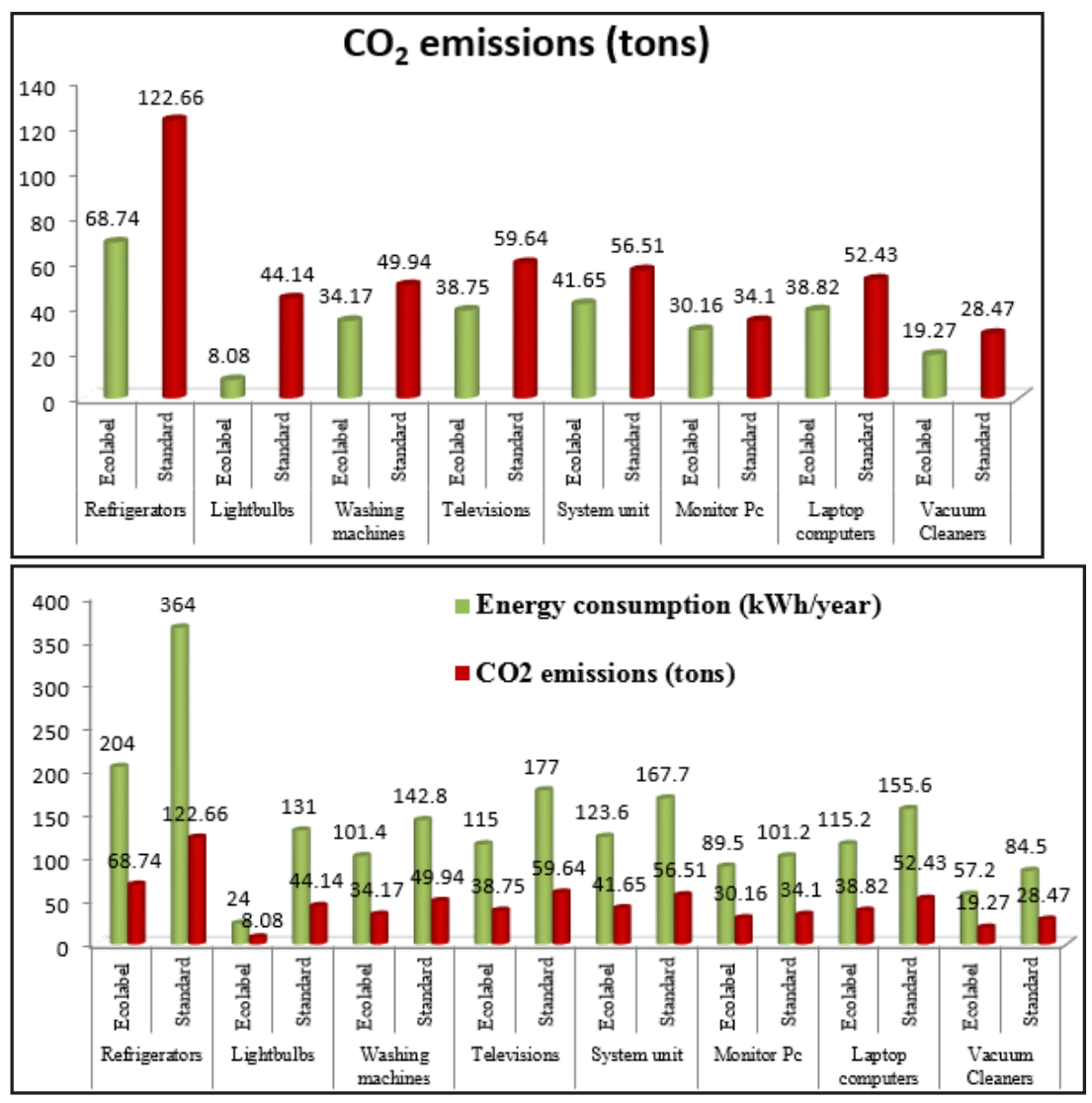

Fig. 2. $\mathrm{CO}_{2}$ emissions (Em) for each product category

Fig. 3. Mean energy consumption (Ec) and $\mathrm{CO}_{2}$ emissions (Em) for each product category

The category with the largest number of available ecoproducts is the televisions one ( 29 different ecolabeled products), while the vacuum cleaners one presents the largest percentage ( $37.8 \%$ of the total number of available products); on the other hand ecolabeled washing machines have a limited availability ( 5 products out of 140), followed by electric lamps ( $9.3 \%$ of the total). Considering the total numbers, eco products are less than the $15 \%$ of the available products of the product categories analysed in the study.

Energy consumption is also an important factor to consider when purchasing a product. It can be seen that the refrigerators and washing machines eco-labeled consumes little energy (electricity consumption is reduced by approximately $53 \%$ for televisions, $45 \%$ for refrigerators and $40 \%$ for washing machines) compared to those withoutecolabel. Ecolabel these products guarantee a high level of performance, a level of noise reduced use of substances with minimal effects on the ozone layer and global warming, ease of disassembly and recycling and parts availability is guaranteed continuous 12 years after production [12, 13].

Regarding electric lamps, power consumption is reduced compared to conventional ones and are produced with durability.

$\mathrm{CO}_{2}$ is the greenhouse gas most commonly produced by human activities and it is responsible for $64 \%$ of manmade global warming. Its concentration in the atmosphere is currently $40 \%$ higher than it was when industrialisation begain [14].

The large range found for the refrigerators category can be explained by the fact that these products have a wide range of technical characteristics in order to satisfy the different needs of the costumers. With regards to the price difference among eco and non-eco products the following scenario was observed (table 2).

Electric lamps, monitor pc and vacuum cleaner are the product categories with the highest mean price difference compared to non-eco products, while for the other categories the additional cost is limited.

\begin{tabular}{|c|c|c|c|}
\hline Product category & Eco-certification & Price product (euro) & Price difference [€] \\
\hline \multirow[t]{2}{*}{ Refrigerators } & Ecolabel & 325.00 & \multirow{2}{*}{75.00} \\
\hline & Standard & 250.00 & \\
\hline \multirow[t]{2}{*}{ Electric lamps } & Ecolabel & 9.00 & \multirow[t]{2}{*}{6.00} \\
\hline & Standard & 3.00 & \\
\hline \multirow[t]{2}{*}{ Washing machines } & Ecolabel & 300.00 & \multirow[t]{2}{*}{35.00} \\
\hline & Standard & 265.00 & \\
\hline \multirow[t]{2}{*}{ Televisions } & Ecolabel & 250.00 & \multirow[t]{2}{*}{40.00} \\
\hline & Standard & 210.00 & \\
\hline \multirow[t]{2}{*}{ System unit } & Ecolabel & 250.00 & \multirow[t]{2}{*}{50.00} \\
\hline & Standard & 200.00 & \\
\hline \multirow[t]{2}{*}{ Monitor Pc } & Ecolabel & 150.00 & \multirow[t]{2}{*}{20.00} \\
\hline & Standard & 130.00 & \\
\hline \multirow[t]{2}{*}{ Laptop Computers } & Ecolabel & 350.00 & \multirow[t]{2}{*}{130.00} \\
\hline & Standard & 220.00 & \\
\hline \multirow[t]{2}{*}{ Vacuum cleaner } & Ecolabel & 110.00 & \multirow[t]{2}{*}{20.00} \\
\hline & Standard & 90.00 & \\
\hline
\end{tabular}

Table 2

PRICE DIFFERENCE (PD) FOR EACH PRODUCT CATEGORY 


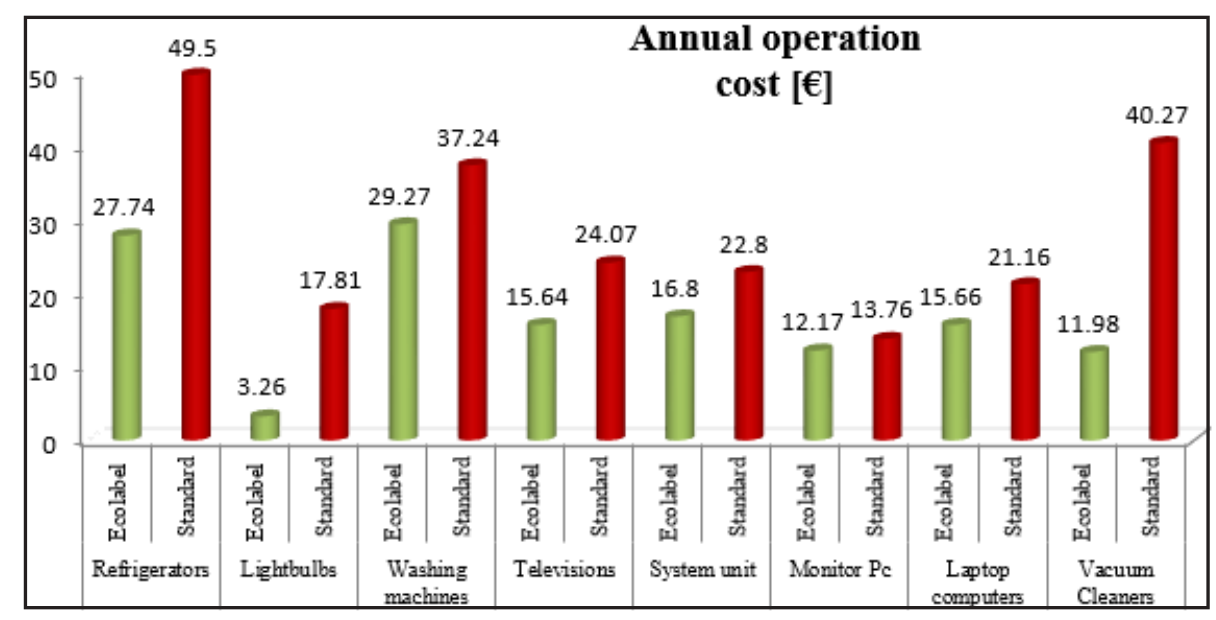

Fig. 4. Annual operation cost $(A O C)$ in euro for the different product categories

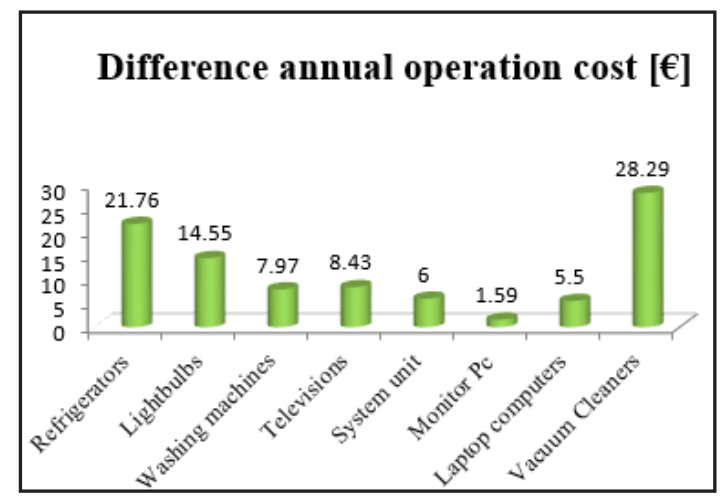

Fig. 5. Difference annual operation cost (AOCD)

Refrigerators and washing machines are the product categories determining the highest mean AOC (fig. 4). The largest range of variation of values in green products is related to the refrigerators category $(27.74 \div 49.5 \in)$ while for the category monitor $p c$ variation is limited $(12.17 \div 13.76 \in)$.

Eco products have a lower annual operational cost $A O C$ than non eco ones; this difference is now quantified by the parameter $A O C D$ (expressed in euro ). The largest range of variation of difference annual operation cost is related to the vacuum cleaners category $(28.29 \in)$ and for the monitor pc category the difference is lower $(1.59 \in)$.

The payback period is the length of time required to recover the cost of an investment. The Investmentthat we investigate is the choice of an eco product instead of a non eco one. The purchase cost of eco products is higher than the purchase cost of non eco ones. The payback period now becomes: in how many years the higher initial purchase cost of the eco product is recovered by its lower annual operational costs. The largest range of variation of payback period is related to the category of laptop computers (23.63 years) and for the lightbulbs category the payback period is lower ( 0.41 years).

\section{Conclusions}

Survey results clearly indicate that eco-labeled products have a higher purchase costs compared to non-eco products, but the payback period is lower because they have a low energy consumption. On the other hand ecolabeled non electric products have a very limited price difference compared to the non-eco ones $(<0.6 \%)$.

Electrical appliances represents approximately $40 \%$ of the electricity consumption of households, a big part of the bill for water and waste generated.

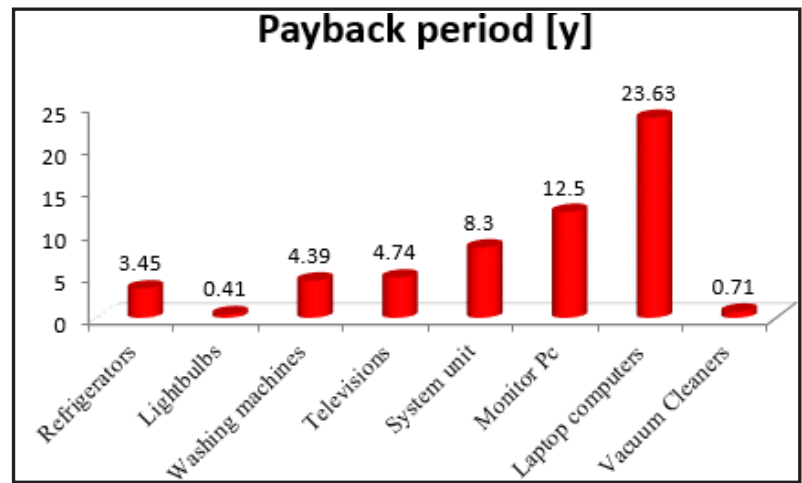

Fig. 6. Payback period (PP) in years

The purpose of the Green Registry is to increase the number of consumers and users through accurate information on the benefits of eco-labeled products. Green products provide, as a whole, a better quality for consumers, since they incorporate the environmental requirements while the production of non-eco products causes serious damage to the environment.

The education of consumers on the consumption of green products will contribute to changing patterns of production and consumption and minimizing human and industrial activities on the environment.

It is necessary to revise he main concerns and openings for a more innovation design of ecoproducts. Many products are designed for international mass markets. The producers have to ensure that the most appropriate and efficient products are available to their markets. A major goal is to improve product performance. Among the main patterns were proposed the priorities addressed to energy, waste and other eco-design aspects of products, taking into account whole-life environmental impacts.

Eco-labels are also considered by manufacturers as a valuable tool to communicate the environmental qualities and quality image of their product and their company. Research has shown that improvements in environmental performance of a product only became a significant competitive factor once competitive levels of product performance, quality and value are attained.

An importantfeature of eco-labeled products is durability of the product, if it is built to withstand. In some cases it seems attractive buying the cheapest product, but in fact it may be the most expensive in the long and harmful to the environment. Products of inferior quality (regardless of their environmental characteristics) tend to have a shorter life. If a cheaper product has to be replaced more often than a more expensive product, this will result in higher costs, extra energy consumption, and more waste. Most attention in terms of environmental performance should 
be given so that he could choose a way as environmentally friendly, taking into account the equipment and materials used.

Acknowledgements: The Promoting Green Products project(LIFE+08/ INF/RO/000507) was financed by the European Commission through the LIFE+ program.

\section{References}

1. J. BANYTE, L. BRAZIONIENE, A. GADEIKIENE, Investigation of Green Consumer Profile: a Case of Lithuanian Market of Eco-Friendly Food Products. Ekonomika ir vadyba - Economics and Management, 15, 2010, 374-383.

2. M. AMSTEL, P. DRIESSEN, P. GLASBERGEN, Eco-labeling and information asymmetry: a comparison of five eco-labels in the Netherlands, Journal of Cleaner Production 16, 2008, 263-276.

3. C. BRATT, S. HALLSTEDT , K.-H. ROBËRT, G. BROMAN, J. OLDMARK, Assessment of eco-labelling criteria development from a strategic sustainability perspective, J ournal of Cleaner Production, 192011 ,1631-1638.

4. S. LAVALLEE, S. PLOUFFE, The eco label and sustainable development, International journal of life cycle assessment, 9, 2004, 349-354.

5. E. REX, H. BAUMANN, Beyond eco labels: what green marketing can learn from conventional marketing, Journal of Cleaner Production, 15, 2007, 567-576.

6. PAS 2050, Specification for the assessment of the life cycle greenhouse gas emissions of goods and services, BSI - DEFRA Carbon Trust 2008.

7. G. ATANASOAIE, Eco-Label and its Role in the Development of Organic Products Market, The Bucharest University of Economics Studies, Romania Economy Transdisciplinarity Cognition , 16, 2013, Issue 1/ 122-129.

8. S. TIWARI , D. MANI TRIPATHI, U. SRIVASTAVA, P.K. YADAV 2, Green marketing - emerging dimensions, Journal of Business Excellence, Vol. 2, 2011, Issue 1, PP-18-23.
9. C. UCENIC, L. BACALI, Attitude of Romanian Consumers and Producers toward Ecological Products, Proceedings of the 2nd IASME I WSEAS International Conference on Energy \& Environment, Portoroz, Slovenia, 7, 2007, May 15-17.

10. GREEN PRO, Promoting green products, LIFE08 INF/RO/000507, GREEN REGISTER MANUAL: With instructions for the database of green products Activity B2, 2011.

11.***Guide to PAS 2050, How to assess the carbon footprint of goods and services, BSI - DEFRA - Carbon Trust, 2008.

12. M. GRIMMER, T. BINGHAM, Company environmental performance and consumer purchase intentions, Journal of business research, 66, 2013, 1945-1953.

13. R. G. ALBU, I. B. CHITU, The European Ecolabel -Advantages And Perspectives For Development In Romania, Bulletin of the Transilvania University of Brasov, 5, 2012, No. 2 .

14. M. PANAINTE, V. INGLEZAKIS, I. CARAMAN, M. NICOLESCU, E. F. MOSNEGUPU, F. M. NEDEFF, The evolution of eco-labeled products in Romania, Environmental Engineering and Management J ournal, 7, 1665-1671.

15. D. GRUNDEY, R. ZAHARIA, Sustainable Incentives in Marketing and Strategic Greening: The Cases of Lithuania and Romania, Technological and Economic Development. Baltic Journal on Sustainability, 14, No.2, 130-143, (2008).

16. V.J. INGLEZAKIS , A. ZORPAS , V. NEDEFF , G. LAZAR , M. PANAINTE, Green products and eco labeling: an EU-project in Romania, Second International Symposium on Green Chemistry for Environment and Health, September 26-29, Mykonos, Greece, 2010. 17. A. TEMEA, C. COMOGLIO, S. BOTTA, V. NEDEFF, M. PANAINTELEHÃDUa , M. DANU, N. BARSAN, Developing a green register of ecolabeled products in Romania, Environmental Engineering and Management J ournal, 15, No. 8, 2016, 1873-1878.

18. GREEN PRO, Promoting green products, LIFE08 INF/RO/000507, Action B1: Market research - Part B: Detailed Methodology 2010.

Manuscript received: 2.02 .2018 